\title{
OPEN Experimental sleep loss, racial bias, and the decision criterion to shoot in the Police Officer's Dilemma task
}

\begin{abstract}
Michael K. Scullin ${ }^{1 \bowtie}$, Michelle R. Hebl' ${ }^{2}$ Abby Corrington ${ }^{3}$ \& Stacy Nguyen ${ }^{1,4}$
Violent behavior, police brutality, and racial discrimination are currently at the forefront of society's attention, and they should be. We investigated whether mild sleep loss-as typical for many adults throughout the work week-could aggravate the socio-emotional-cognitive processes contributing to violence and discrimination. In a sample of $\mathbf{4 0}$ healthy young adults, we either experimentally restricted participants' sleep for four nights ( $6.2 \mathrm{~h} / \mathrm{night}$ ) or let participants obtain normal sleep $(7.7 \mathrm{~h} /$ night)-and then had them complete the Police Officer's Dilemma Task. In this computerized task, the participant must rapidly decide to shoot or not shoot at White and Black men who either are or are not holding a gun. Results showed significant racial biases, including more and quicker shooting of Black targets compared to White targets. Furthermore, signal detection analyses demonstrated that mild sleep restriction changed participants' decision criterion, increasing the tendency to shoot, even when controlling for psychomotor vigilance, fluid intelligence, and self-reported desirability to behave in a socially acceptable manner. The increased tendency to shoot was also observed in participants who reported believing that they had adapted to the sleep loss. Future experimental research using trained police officers will help establish the generalizability of these laboratory effects. Importantly, sleep loss is modifiable via organization-level changes (e.g., shift scheduling, light entrainment) and individual-level interventions (e.g., sleep hygiene education, incentives for behavioral change), suggesting that if sleep loss is corrected, it could save lives-including Black lives.
\end{abstract}

On the night of September 6, 2018, a White police officer returned to what she believed was her apartment, opening the door to find Mr. Botham Jean, a Black man. The officer, Amber Guyger, quickly pulled her gun and shot him in the chest, killing him. Botham Jean was unarmed and simply eating ice cream in his own-not the officer's-apartment ${ }^{1}$. At the trial, it was revealed that the police officer was "fatigued" from having worked $40 \mathrm{~h}$ in the previous four days, including just finishing a shift that lasted at least $13 \mathrm{~h}^{2}$. While there are many racial bias-related components of the Guyger/Jean case and other police shootings that warrant empirical investigation, the observation that Guyger was "fatigued" at the time of the shooting should be of particular interest to sleep researchers.

Chronic sleep loss has been called an "epidemic", with some estimating that sleep in United States citizens has dropped from nearly $8 \mathrm{~h} /$ night in the 1940 s to 7 or fewer hours/night more recently ${ }^{3,4}$. Sleep loss is common among people of many different professions, but because police officers carry firearms and often must handle potentially hostile situations, it is crucial to recognize that their shifts can be particularly long, variable, and circadian-misaligned ${ }^{5}$. In a large, representative sample, $40 \%$ of police officers had clinical-level sleep disorders and more than $1 / 4$ of officers reported falling asleep while driving at least once per month ${ }^{6}$. Such widespread sleep loss-whether in police officers or any other citizen-is likely to be consequential. After all, acute and chronic sleep loss are known to have numerous neurobiological consequences for nearly all people (i.e., only a small percentage of the population can maintain short sleep without consequences ${ }^{7}$ ).

In the current work, we investigated sleep loss as a potent mechanism for altering socio-emotional-cognitive processes, which could then correspond to increased expressions of biases and discrimination ${ }^{8}$. Discrimination is, of course, driven by prejudice and racism, but there are at least three additional mechanisms by which sleep deprivation could contribute to when and how discrimination manifests. First, sleep deprivation can alter frontoparietal attentional network functioning ${ }^{9,10}$. For decades, researchers have known that sleep restriction slows responding and increases lapses of attention ${ }^{11,12}$. Relatedly, if one's attentional resources are depleted, then they

${ }^{1}$ Department of Psychology and Neuroscience, Baylor University, One Bear Place 97334, Waco, TX 76798, USA. ${ }^{2}$ Department of Psychological Sciences, Rice University, Houston, TX, USA. ${ }^{3}$ Department of Management, Providence College School of Business, Providence, RI, USA. ${ }^{4}$ School of Medicine, University of Texas Health Sciences Center, San Antonio, TX, USA.『email: Michael_Scullin@Baylor.edu 


\begin{tabular}{|l|l|l|l|}
\hline \multicolumn{2}{|l|}{ Restricted sleep(n=20) } & Normal sleep(n=20) & Statistic \\
\hline Monday measures (session 1) & $21.20 \pm 2.19$ & $20.25 \pm 1.48$ & $t(38)=1.61, p=.12$ \\
\hline Age (years) & $60 \%$ & $70 \%$ & $\mathrm{X}^{2}(1)=0.44, p=.51$ \\
\hline Gender (\% female) & $55 \%$ & $45 \%$ & $\mathrm{X}^{2}(1)=0.40, p=.53$ \\
\hline Race/ethnicity (\%White) & $17.50 \pm 4.90$ & $15.85 \pm 4.60$ & $t(38)=1.097, p=.28$ \\
\hline Social Desirability Scale & $5.25 \pm 2.51$ & $5.25 \pm 2.27$ & $t(38)<.01, p>.99$ \\
\hline Pittsburgh Sleep Quality Index & $4.35 \pm 1.79$ & $5.21 \pm 1.55$ & $t(38)=1.60, p=.12$ \\
\hline Karolinska Sleepiness Scale & $92.10 \pm 17.16$ & $90.25 \pm 11.76$ & $t(38)=0.40, p=.69$ \\
\hline Profile of mood states - total mood disturbance & & $461.73 \pm 42.64$ & $t(38)=5.87, p<.001$ \\
\hline Friday measures (session 2) & $372.56 \pm 52.95$ & -- & \\
\hline Total sleep time (actigraphy minutes) & $40 \%$ & $3.15 \pm 1.53$ & $t(38)=4.02, p<.001$ \\
\hline Perceived they adapted to sleep loss (\%) & $5.30 \pm 1.83$ & $94.90 \pm 18.06$ & $t(38)=2.40, p=.021$ \\
\hline Karolinska Sleepiness Scale & $111.35 \pm 24.74$ & $t(38)=2.16, p=.037$ \\
\hline Profile of mood states - total mood disturbance & $325.13 \pm 50.02$ & $11.10 \pm 2.55$ & $t(38)=0.76, p=.76$ \\
\hline Psychomotor vigilance task-response times & $10.80 \pm 3.44$ & & \\
\hline Raven's progressive matrices (of 18) & & $294.07 \pm 40.27$ & \\
\hline
\end{tabular}

Table 1. Sample characteristics and task performance. Data are plotted as mean \pm standard deviation, with measures separated by Monday (Session 1) and Friday (Session 2) data collection. The conditions did not differ pre-experimentally (Session 1), but showed strong differences in sleep duration, daytime sleepiness, mood disturbances, and vigilance by the end of the week.

may lack the ability to inhibit prejudices they hold that are typically suppressed ${ }^{13}$. Second, sleep deprivation can increase emotional reactivity. In one experiment, participants either slept normally or were sleep deprived and then shown negative images (e.g., snake attacking, person holding a gun). Sleep deprivation increased amygdala reactivity to the negative images due to decreased connectivity between the medial prefrontal cortex and the amygdala ${ }^{14}$. Third, sleep deprivation can alter threat perceptions. In a recent study, participants who either were sleep deprived or had normal sleep were shown a series of faces and asked to classify them as threatening or nonthreatening ${ }^{15}$. Following sleep deprivation, more faces were rated as threatening, a pattern that corresponded to activity in the salience detection network ${ }^{8}$. Whether sleep deprivation's effects on attention, emotional reactivity, or threat perception translate to greater discrimination following sleep loss has received minimal empirical study and remains poorly understood ${ }^{16-21}$.

\section{Results}

To mirror the chronic mild sleep loss experienced by many individuals during the work week, we randomly assigned 40 healthy adult participants (ages 18-27, 66.7\% female, 52.4\% White, $31.0 \%$ Asian, 14.3\% Hispanic, $2.4 \%$ Mixed, $0 \%$ Black) to maintain a bedtime of either $10: 30 \mathrm{pm}$ or 1:30 am from Monday to Friday ${ }^{22}$. Waketime was set to 7:30 am each day. By using sealed envelopes and blocked randomization, experimenters and analysts remained blinded to participants' randomly assigned normal versus restricted sleep conditions. The normal sleep condition averaged $1.5 \mathrm{~h}$ more sleep per night than the restricted sleep condition, $t(38)=5.87, p<0.001$, $d=1.85$ (Table 1). Furthermore, by Friday, the sleep restricted participants experienced greater daytime sleepiness $[t(38)=4.02, p<0.001, d=1.27]$, greater moodiness $[t(38)=2.40, p=0.021, d=0.76]$, and poorer sustained attention (assessed using the psychomotor vigilance task; $t(38)=2.16, p=0.037, d=0.68$; Table 1 ). We did not measure explicit prejudices to avoid demand characteristics.

The Friday test session ${ }^{22}$ concluded with the Police Officer's Dilemma Task ${ }^{23,24}$. This task was developed to simulate the real-world challenge of police officers needing to make quick decisions in response to perceptually ambiguous situations (i.e., threatening or non-threatening). Participants were shown scenes that were either empty (no person) or contained a target (person). The target person was either unarmed or armed with a gun and either White or Black, and participants had to quickly decide whether to shoot or not shoot the target. We analyzed accuracy, reaction times, timeouts (failures to respond within the time limit), and signal-detectiontheory metrics by conducting a series of $2 \times 2$ analyses of variance (ANOVAs) that included target race (White, Black) and sleep condition (normal, restricted).

The results revealed significant evidence for racial biases. On armed trials, participants were more likely to "shoot" Black targets than White targets (Fig. 1A), $F(1,38)=5.37, p=0.026, \eta_{\mathrm{p}}{ }^{2}=0.12$, and with quicker response times (Fig. 1B), $F(1,38)=4.13, p=0.049, \eta_{\mathrm{p}}{ }^{2}=0.10$. On unarmed trials, there were no effects for mean response times ( $p s>0.10)$, but there were far more failures to respond within time limits (timeouts) for Black targets than White targets (Fig. 1C), $F(1,38)=19.63, p<0.001, \eta_{\mathrm{p}}{ }^{2}=0.34$. This result suggests that participants experienced greater difficulty in quickly identifying the Black targets as non-threatening. Similarly, there were significantly fewer "don't shoot" responses to unarmed Black targets than unarmed White targets (Fig. $1 D$ ), $F(1,38)=11.45$, $p=0.002, \eta_{\mathrm{p}}{ }^{2}=0.23$. False alarms were rare and showed nonsignificant effects. We conducted follow-up analyses to determine whether any of the significant effects interacted with gender. All gender main effects and interactions were nonsignificant ( $p s>0.05$ ), indicating that men and women demonstrated similar levels of racial biases in the 
A

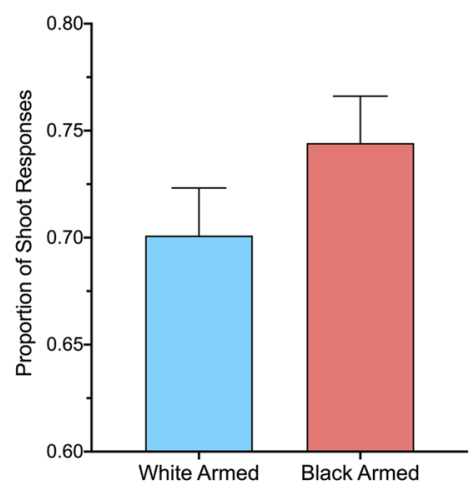

\section{Armed Targets (Threatening)}

B

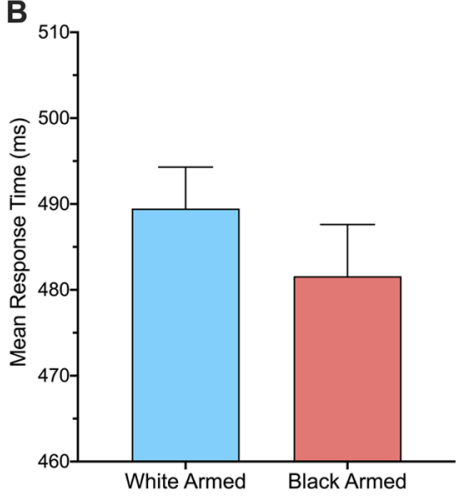

Unarmed Targets (Non-Threatening)

C

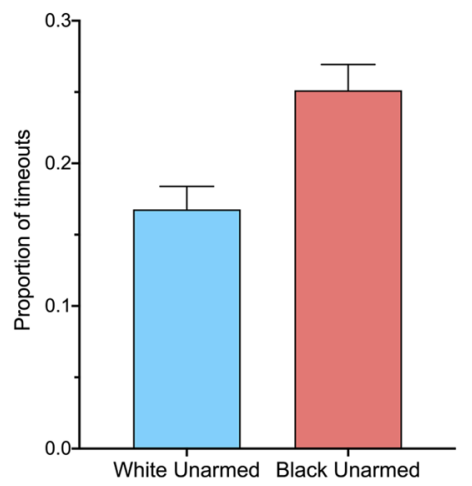

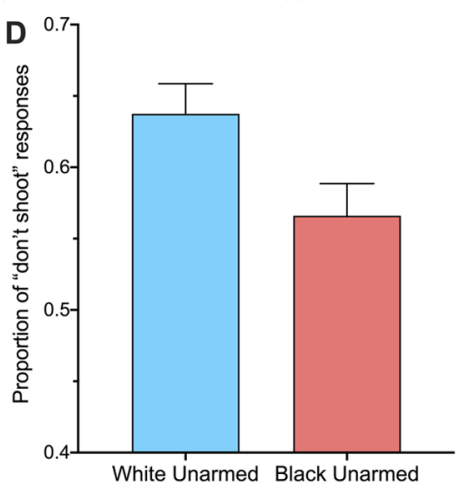

\section{Signal Detection Analyses}
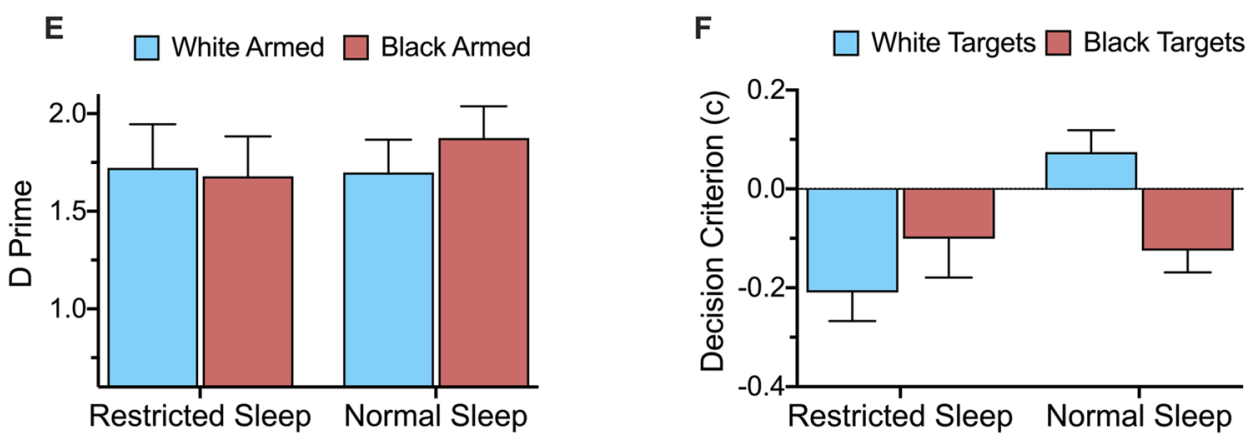

Figure 1. Performance on the Police Officer's Dilemma Task. There was evidence for racial bias in response latencies and shoot responses on threatening target trials $(\mathbf{A}, \mathbf{B})$ as well as indecision and absence of non-shoot responses on non-threating target trials $(\mathbf{C}, \mathbf{D})$. Sleep restriction was unrelated to $d^{\prime}$ sensitivity $(\mathrm{E})$, but altered the decision criterion for shooting toward leniency $(\mathbf{F})$. Data shown as mean \pm SEM.

Police Officer's Dilemma Task. The averaged accuracy and averaged response time metrics were not significantly affected or moderated by sleep condition $(p s>0.05)$.

An effect of sleep condition emerged when conducting analyses based on signal detection theory. We distinguished sensitivity to armed targets $\left(d^{\prime}\right)$ and the decision criterion $(c)$ for shooting a target. Similar to previous reports $^{24}$, there were no significant effects on $d^{\prime}$ (Fig. 1E; $p s>0.10$ ). Importantly, for $c$, there was a significant main effect of sleep condition such that sleep restriction $(M=-0.155)$ caused greater leniency in shooting targets relative to normal sleep $(M=-0.025), F(1,38)=4.63, p=0.038, \eta_{\mathrm{p}}{ }^{2}=0.11$. Criterion scores were significantly lower than zero after sleep restriction, $t(19)=3.20, p=0.005, d=1.47$, but did not differ significantly from zero after normal sleep, $t(19)=0.49, p=0.49, d=0.22$. Figure $1 \mathrm{~F}$ further illustrates that sleep condition interacted with target race, $F(1,38)=7.75, p=0.008, \eta_{\mathrm{p}}{ }^{2}=0.17$. Being well-rested led to a more conservative criterion for White targets, $t(38)=3.89, p<0.001, d=1.23$, but this benefit of rested sleep did not extend to Black targets, $t(38)=0.27$, $p=0.79, d=0.09$. In other words, all groups showed a lenient bias except for well-rested participants' responses 
to White targets. The interaction remained statistically significant even when controlling for participants' psychomotor vigilance, fluid intelligence, self-reported desirability to behave in a socially acceptable manner, and self-reported belief that they had adapted to the sleep loss, $F(1,34)=6.07, p=0.019, \eta_{\mathrm{p}}{ }^{2}=0.15$.

The effects of sleep restriction and target race on decision criterion were not moderated by gender, $F(1$, $36)=0.74, p=0.40, \eta_{\mathrm{p}}{ }^{2}=0.02$ (and there were no interactions; all $F s<1$ ). Women and men showed identically lenient $c$ scores after sleep restriction $\left[M s=-0.158\right.$ and -0.151 , respectively, $\left.F(1,18)=0.004, p=0.95, \eta_{\mathrm{p}}{ }^{2}<0.01\right]$ and similar $c$ scores after normal sleep $\left(M s=-0.056\right.$ and 0.048 , respectively, $\left.F(1,18)=1.84, p=0.19, \eta_{\mathrm{p}}{ }^{2}=0.09\right)$. Interestingly, when limiting the sample to only White participants, the sleep restriction effects on decision criterion were exacerbated. For example, the effect size increased from $\eta_{\mathrm{p}}{ }^{2}=0.11$ in the overall sample to $\eta_{\mathrm{p}}{ }^{2}=0.37$ in only the White participants, $F(1,18)=10.50, p=0.005$. The sleep by race interaction also increased in effect size from $\eta_{\mathrm{p}}{ }^{2}=0.17$ in the overall sample to $\eta_{\mathrm{p}}{ }^{2}=0.39$ in the White participants, $F(1,18)=11.64, p=0.003$.

\section{Discussion}

To promote social justice, society must address violent behavior, police brutality, and racial discrimination. The current data suggest that some of these behaviors may be exacerbated by sleep loss, even when the sleep restriction is relatively mild ( $6.2 \mathrm{~h} /$ night), even when sleep restricted individuals believe they have "adapted" to the short sleep, and even in individuals with inclinations toward behaving in a socially desirable manner.

The current experimental findings provide causal support for an earlier correlational study in newly recruited police officers ${ }^{21}$. In Ma et al.'s ${ }^{21}$ study, newly recruited officers with self-reported total sleep time -1 SD below the mean $(\leq 5.25 \mathrm{~h})$ showed greater racial bias in the shooter task than officers with self-reported total sleep time +1 $\mathrm{SD}$ above the mean $(\geq 8.05 \mathrm{~h})$. Both their study and the current results implicated sleep loss in more "itchy trigger finger" type responding. A distinction in the studies, however, was that Ma et al. ${ }^{21}$ found that short sleepers were more likely to show a lenient decision criterion toward Black targets, whereas we found sleep restriction affected the decision criterion primarily for White targets. In another recent study ${ }^{25}$, total sleep deprivation ("all nighter") in college student participants led to more errors on the Police Officer's Dilemma Task, particularly more "shooting" of unarmed targets (but not in a racially biased manner). These effects were not mitigated by caffeine consumption. The differences across these data sets and our results could be due to study differences in experimental/correlational design, sample size, sleep measurement, type of sleep loss (acute, chronic), sample composition (e.g., young adults tend to be more open and liberal), or other factors that might become evident with further studies.

Our findings also join a growing literature that implicates short and poor-quality sleep in stereotyping and bias toward out-groups ${ }^{13,16-18}$, perhaps in a circadian-sensitive manner ${ }^{19,20}$. Sleep deprivation might lead to increased manifestations of discrimination by altering frontoparietal attentional processes ${ }^{9,10}$, amygdala/emotional reactivity processes ${ }^{8,14}$, and/or threat perception processes ${ }^{15,26}$. The first potential mechanism-altered frontoparietal attentional processes-relates to Ghumman and Barnes ${ }^{13}$ idea that resources are needed to maintain control over prejudices, and if such resources are depleted by sleep loss, then biases and discriminatory behaviors will manifest. This idea is logical, but we did not observe direct evidence for it in the current study. When we controlled for performance on psychomotor vigilance and fluid intelligence tasks, we continued to observe that sleep restriction affected the decision criterion to shoot.

Distinguishing the amygdala/emotional reactivity and threat perception accounts is trickier because these views predict fairly similar outcomes. For example, sleep loss may make one react more emotionally to negative stimuli, manifesting in this paradigm as "shoot" responses on armed target trials. However, if threat perception is elevated after sleep loss, then "shoot" responses should increase across both armed and unarmed target trials. The collective data on decision criterion, therefore, favored the altered threat perception account. Nonetheless, we cannot dismiss the possibility that sleep loss also affects the decision criterion to shoot via amygdala/emotional reactivity, inhibitory inefficiency, impulsivity, altered ethical decision making, or general tendencies toward aggression $^{26-32}$, accounts which are not necessarily mutually exclusive with the altered threat perception account.

The purpose of the current study was to investigate the causal effects of sleep loss on socio-emotional-cognitive processes that could contribute to racial discrimination. Another emerging literature that connects sleep and racial discrimination falls under the umbrella of health disparities. Health disparities refer to group differences in disease rates/outcomes that are systematic, avoidable, and unfair ${ }^{33}$. For example, the Centers for Disease Control and Prevention ${ }^{34}$ report that Black or African American individuals have considerably higher rates of diabetes, hypertension, heart disease, and HIV infection than White and Asian American individuals (disparities are also observed for Hispanic/Latinx individuals as well as American Indian/Alaska Native individuals) ${ }^{35,36}$.

One of the leading models for explaining health disparities points to upstream determinants influencing downstream determinants. Upstream determinants refer to fundamental social/environmental causes, including differences in socioeconomic status, discrimination, and other societal inequities. Downstream determinants refer to the individual's experiences and can include allostatic load, self-determination, and health behaviors (note that models also indicate that gene-environment interactions feed back to upstream factors ${ }^{37,38}$. Pertinent to the present work, racial/ethnic differences in sleep health are recognized as markers of health disparities (i.e., sleep disparities $)^{39-47}$. Furthermore, sleep disparities are emerging as an important contributor to race/ethnic disparities in cardiovascular ${ }^{48-52}$, metabolic ${ }^{52,53}$, and cognitive ${ }^{54,55}$ health outcomes. Clearly, sleep health is important in all communities, even when isolated from matters of violence and aggressive race-based discrimination.

One of the limitations of the current study was the sample size, including a limited number of participants from non-White groups. On the one hand, this limitation does not undermine the primary purpose of understanding how majority groups (White participants) display racial biases and altered behaviors under mild sleep restriction (note that police officers in the U.S. are disproportionately White relative to Census estimates ${ }^{56}$ ). On the other hand, the limited variability in participant demographics hindered us from examining whether effects 
were driven by in-group/out-group determinant ${ }^{57,58}$ versus general stereotyping of Black men ${ }^{59}$. Increasing diversity in participant enrollment is a longstanding problem in both psychological and medical research ${ }^{60-62}$. Overcoming barriers to participant representation requires additional time and monetary resources for recruitment, collaboration with community leaders, and cultural tailoring ${ }^{62,63}$. It also requires increasing representation at the level of scientists, editors, and funding agencies ${ }^{64,65}$. In other words, academia as a whole must acknowledge and work to address its own systematic biases.

\section{Conclusions and future directions}

Police work is one of the most sleep-depriving professions ${ }^{5,6}$. It is also one of the few professions that involves carrying firearms and encountering potentially hostile situations. It remains an open, empirical question whether the gun-safety training offered to police officers shields them from the deleterious effects of sleep loss. Though that is possible, we note the following empirical evidence: (1) shielding was not observed in a correlational study on sleep and shooter bias in newly recruited police officers ${ }^{21}$; $(2)$ night shift patrol officers were less likely to prevent deadly outcomes in video-based use-of-force simulators than day shift patrol officers ${ }^{66}$; (3) police officers sleep even worse than the general public ${ }^{5,6}$; and (4) workers in other fields that require extensive, safety-focused training (e.g., medicine) still show susceptibility to sleep loss and shift-work fatigue ${ }^{67-70}$. Therefore, sleep loss deserves closer consideration by public officials and law enforcement as an insidious culprit underlying people's sometimes faulty judgments and impulsive behaviors.

To eliminate discriminatory behaviors in society-including the shooting of unarmed Black individualsthere will be no substitute for eliminating underlying racism within individuals and systems. To achieve this end, education, policy changes, and individual efforts will be key. But, we also contend that there is room for reducing sleep debt in society ${ }^{3,71,72}$. Workplace sleep education programs ${ }^{73}$, behavioral change programs ${ }^{74}$, $\operatorname{tar}^{-}$ geted memory reactivation interventions ${ }^{75}$, culturally tailored and personalized programs $\mathrm{s}^{76-78}$, and schedules allowing for circadian alignment ${ }^{79}$ have all been shown to be effective. Based on the current results, as well as the literature on health disparities, it appears that correcting sleep loss in society may play a significant role in saving lives, including Black lives.

\section{Methods}

Participants. Forty-six adult participants were recruited through flyers and social media advertisements in spring 2018. The sample size was determined a priori to detect a large condition effect size, as often observed in sleep restriction studies ${ }^{16,80}$. They received monetary compensation for participating. Advertisements referred to the study as examining Sleep and Social Cognition to prevent expectation effects that would have emerged if the study were advertised as testing racial biases. Exclusion criteria included being under age 18 or over the age of 30 , being a habitual short sleeper ( $<7 \mathrm{~h}$ per night), and having clinically-diagnosed sleep disorders. Two participants did not complete all study sessions. Because there were only four African American participants we were unable to examine in-group versus out-group effects in this study; therefore, we excluded those data from the Police Officer's Dilemma Task analyses (their data were included in other measures collected as part of this larger sleep study ${ }^{22}$ ). The study was approved by the Baylor University Institutional Review Board and all research was performed in accordance with relevant guidelines/regulations. All participants signed informed consents prior to the study and were debriefed upon study completion.

Overview of design. The 5-day study consisted of two $1.5 \mathrm{~h}$ in-lab experimental sessions - one on Monday and one on Friday. For the four nights between each session, participants were instructed to maintain a wake time of 7:30 am and were randomly assigned to maintain a bedtime of either 10:30 pm (normal sleep condition) or 1:30 am (restricted sleep condition). To promote ecological validity, participants slept in their home environment (home-based and lab-based sleep restriction protocols produce similar effect sizes on cognitive functioning ${ }^{80}$ ). Across the week, we measured sleep using wristband actigraphy, which is designed to detect ambient light and movement (accelerometer-based).

Equipment. The actigraphy device was the Actiwatch Spectrum Plus (Phillips Respironics Actiwach-2), which has been validated for distinguishing sleep/wake state against the gold standard of polysomnography ${ }^{81,82}$. The device was set to factory recommended settings that defined epoch length as $15 \mathrm{~s}$, wake onset as 40 activity counts, and sleep as periods of rest with $10 \mathrm{~min}$ without movement. Participants also maintained a sleep diary ${ }^{83}$.

Session 1. At Session 1 (Monday), participants completed a series of questionnaires. We measured recent sleep quality (Pittsburg Sleep Quality Index ${ }^{84}$ ), daytime sleepiness (Karolinska Sleepiness Scale ${ }^{85}$ ), social desirability ${ }^{86}$, and mood disturbances (Profile of Mood States ${ }^{87}$ ). Participants additionally completed three cognitive tests: the psychomotor vigilance test ${ }^{12}$, reading span $^{88}$, and Raven's Advanced Progressive Matrices ${ }^{89}$. At the end of Session 1 , participants received the actigraphy device and sleep diary, and they were randomly assigned to the normal sleep and restricted sleep conditions. Assignment order was determined using the blocked random assignment method (blocks of 2,4) using the sealedenvelope.com online tool. To minimize the risk of experimenter bias, the researchers who interacted with the participants were masked to each participant's experimental condition. We accomplished masking by having a research staff member who would not be interacting with participants generate the random assignments and seal participants' condition assignments in envelopes. Only after participants completed Session 1, did a research staff member hand the participant a sealed envelope with their condition with the instruction to open the envelope after leaving Session 1. Participants were explicitly instructed to not mention their assigned sleep condition to the experimenter as they were leaving or when they returned for Session 2. Participants were instructed not to nap during the week. 
Session 2. At Session 2 (Friday), participants returned to the laboratory at the same time as on Monday (typically, 8:30 am). We asked participants if they believed they had adapted to the sleep loss, and then readministered the daytime sleepiness scale, mood disturbances scale, cognitive measures, and a medical error vignette $\operatorname{task}^{22}$. Lastly, participants completed the Police Officer's Dilemma Task, administered via E-prime 2.0 software. In this task, participants are shown scenes with armed and unarmed men (targets) who are either White or Black ${ }^{23,24}$. The participant's objective is to shoot (Q key) the armed targets and to not shoot (P key) the unarmed targets. Armed targets are holding either a revolver or a pistol, whereas unarmed targets are holding an aluminum can, a camera, a cell phone, or a wallet. In the procedure, empty scenes continuously flash in 500$1000 \mathrm{~ms}$ intervals, and after 1-4 empty scenes, a target scene will appear. After 16 practice trials, participants completed 100 experimental trials (25 White armed trials, 25 White unarmed trials, 25 Black armed trials, and 25 Black unarmed trials). To simulate the speeded nature of real world dilemmas, participants had to respond within $630 \mathrm{~ms}$, otherwise the trial resulted in a timeout ${ }^{90}$. Response times were analyzed on correct trials. Accuracy data produced estimates for correct hits (shooting an armed target), misses (not shooting an armed target), false alarms (shooting an unarmed target), and correct rejections (not shooting an unarmed target). Following previous methods ${ }^{24}$, we subjected these accuracy data to signal detection analyses to produce estimates of $d^{\prime}$, which reflects sensitivity, or the ability to discriminate armed from unarmed targets (which typically does not differ across White and Black targets ${ }^{24}$ ). We also generated estimates of decision criterion, or $c$, which reflects the threshold one sets for making a shoot response. Positive $c$ values indicate a conservative threshold, such that one favors a don't-shoot response; negative $c$ values indicate a lenient threshold akin to having an "itchy trigger finger." Signal detection estimates ( $d^{\prime}$ and $c$ ) were calculated separately for White targets and Black targets.

Statistical analyses. Statistical analyses were completed using SPSS 26 (IBM) and graphically displayed using Prism 8.4 (Graphpad). D prime was calculated as $d^{\prime}=\mathrm{zH}=\mathrm{ZFA}$ and criterion was calculated as $c=-0.5$ $\mathrm{X}(\mathrm{zFA}+\mathrm{zH})$. For both calculations, $\mathrm{zFA}$ refers to the $\mathrm{z}$-score of false alarms and $\mathrm{zH}$ refers to the $\mathrm{z}$-score for hits (with minimum and maximum set to $1 / 2 \mathrm{n}$ and $1-1 / 2 \mathrm{n}$, following ${ }^{24}$ ). We conducted a series of $2 \times 2$ mixed analyses of variance (ANOVA) in which condition (normal, restricted) varied between subjects and target race (White, Black) varied within subjects. Alpha was set to 0.05 and all tests were two-tailed. Effect sizes were estimated using Cohen's $d$ and partial eta squared.

\section{Data availability}

Materials for the Police Officer's Dilemma Task are publicly available (http://psych.colorado.edu/ jclab/FPST. html). Additional study materials and raw data are available at the Open Science Framework (https://osf.io/ v9arg/).

Received: 3 July 2020; Accepted: 12 November 2020

Published online: 25 November 2020

\section{References}

1. Allyn, B. Ex-Dallas Officer Who Killed Man in His Own Apartment is Found Guilty of Murder. National Public Radio. https:// www.npr.org/2019/10/01/765788338/ex-dallas-officer-who-killed-neighbor-in-upstairs-apartment-found-guilty-of-murd (2019).

2. Martinez, M. T., \& Fernandez, M. Trial opens for former officer who killed unarmed black man in his apartment. New York Times. https://www.nytimes.com/2019/09/23/us/amber-guyger-dallas-police.html (2019).

3. Walker, M. P. A societal sleep prescription. Neuron 103, 559-562 (2019).

4. Gao, C., Terlizzese, T. \& Scullin, M. K. Short sleep and late bedtimes are detrimental to educational learning and knowledge transfer: an investigation of individual differences in susceptibility. Chronobiol. Int. 36, 307-318 (2019).

5. Garbarino, S., Guglielmi, O., Puntoni, M., Bragazzi, N. L. \& Magnavita, N. Sleep quality among police officers: implications and insights from a systematic review and meta-analysis of the literature. Int. J. Environ. Res. Public Health 16, 885 (2019).

6. Rajaratnam, S. M. et al. Sleep disorders, health, and safety in police officers. JAMA 306, 2567-2578 (2011).

7. He, Y. et al. The transcriptional repressor DEC2 regulates sleep length in mammals. Science 325, 866-870 (2009).

8. Simon, E. B., Vallat, R., Barnes, C. M. \& Walker, M. P. Sleep loss and the socio-emotional brain. Trends Cogn. Sci. 24, 435-450 (2020).

9. Ma, N., Dinges, D. F., Basner, M. \& Rao, H. How acute total sleep loss affects the attending brain: a meta-analysis of neuroimaging studies. Sleep 38, 233-240 (2015).

10. Scullin, M. K. Do older adults need sleep? A review of neuroimaging, sleep, and aging studies. Curr. Sleep Med. Rep. 3, 204-214 (2017).

11. Dinges, D. F. \& Powell, J. W. Microcomputer analyses of performance on a portable, simple visual RT task during sustained operations. Behav. Res. Methods Instrum. Comput. 17, 652-655 (1985).

12. Basner, M. \& Dinges, D. F. Maximizing sensitivity of the psychomotor vigilance test (PVT) to sleep loss. Sleep 34, 581-591 (2011).

13. Ghumman, S. \& Barnes, C. M. Sleep and prejudice: a resource recovery approach. J. Appl. Soc. Psychol. 43, E166-E178 (2013).

14. Yoo, S. S., Gujar, N., Hu, P., Jolesz, F. A. \& Walker, M. P. The human emotional brain without sleep-a prefrontal amygdala disconnect. Curr. Biol. 17, R877-R878 (2007).

15. Goldstein-Piekarski, A. N., Greer, S. M., Saletin, J. M. \& Walker, M. P. Sleep deprivation impairs the human central and peripheral nervous system discrimination of social threat. J. Neurosci. 35, 10135-10145 (2015).

16. Alkozei, A. et al. Chronic sleep restriction increases negative implicit attitudes toward Arab Muslims. Sci Rep. 7, 4285 (2017).

17. Alkozei, A. et al. Chronic sleep restriction affects the association between implicit bias and explicit social decision making. Sleep Health 4, 456-462 (2018).

18. Zhang, J., Yang, Y., \& Hong, Y. Y. Sleep deprivation undermines the link between identity and intergroup bias. Sleep. 43, zsz213 (2020).

19. Bodenhausen, G. V. Stereotypes as judgmental heuristics: evidence of circadian variations in discrimination. Psychol. Sci. 1, 319-322 (1990).

20. Zadra, J. R. \& Proffitt, D. R. Implicit associations have a circadian rhythm. PLoS ONE 9, el10149 (2014).

21. Ma, D. S. et al. When fatigue turns deadly: the association between fatigue and racial bias in the decision to shoot. Basic Appl. Soc. Psychol. 35, 515-524 (2013). 
22. Nguyen, S., Corrington, A., Hebl, M. R. \& Scullin, M. K. Endorsements of surgeon punishment and patient compensation in rested and sleep-restricted individuals. JAMA Surg. 154, 555-557 (2019).

23. Correll, J., Park, B., Judd, C. M. \& Wittenbrink, B. The police officer's dilemma: using ethnicity to disambiguate potentially threatening individuals. J. Pers. Soc. Psychol. 83, 1314-1329 (2002).

24. Correll, J. et al. Across the thin blue line: police officers and racial bias in the decision to shoot. J. Pers. Soc. Psychol. 92, 1006-1023 (2007).

25. Johnson, D. J., Stepan, M. E., Cesario, J. \& Fenn, K. M. Sleep deprivation and racial bias in the decision to shoot: a diffusion model analysis. Soc. Psychol. Pers. Sci. (2020).

26. Zenses, A. K., Lenaert, B., Peigneux, P., Beckers, T. \& Boddez, Y. Sleep deprivation increases threat beliefs in human fear conditioning. J. Sleep Res. 29, e12873 (2020).

27. Kamphuis, J., Meerlo, P., Koolhaas, J. M. \& Lancel, M. Poor sleep as a potential causal factor in aggression and violence. Sleep Med. 13, 327-334 (2012).

28. Anderson, C. \& Platten, C. R. Sleep deprivation lowers inhibition and enhances impulsivity to negative stimuli. Behav. Brain Res. 217, 463-466 (2011).

29. Chuah, Y. L., Venkatraman, V., Dinges, D. F. \& Chee, M. W. The neural basis of interindividual variability in inhibitory efficiency after sleep deprivation. J. Neurosci. 26, 7156-7162 (2006).

30. Drummond, S. P., Paulus, M. P. \& Tapert, S. F. Effects of two nights sleep deprivation and two nights recovery sleep on response inhibition. J. Sleep Res. 15, 261-265 (2006).

31. Barnes, C. M., Schaubroeck, J., Huth, M. \& Ghumman, S. Lack of sleep and unethical conduct. Organ. Behav. Hum. Decis. Process. 115, 169-180 (2011).

32. Barnes, C. M., Awtrey, E., Lucianetti, L. \& Spreitzer, G. Leader sleep devaluation, employee sleep, and unethical behavior. Sleep Health 6, 411-417 (2020).

33. McCartney, G., Popham, F., McMaster, R. \& Cumbers, A. Defining health and health inequalities. Public Health 172, 22-30 (2019).

34. Meyer, P. A., Yoon, P. W. \& Kaufmann, R. B. Introduction: CDC health disparities and inequalities report-United States, 2013. MMWR Suppl. 62, 3-5 (2013).

35. Centers for Disease Control and Prevention. Health disparities experienced by Hispanics-United States. MMWR. 53, 935-937 (2004).

36. Sarche, M. \& Spicer, P. Poverty and health disparities for American Indian and Alaska Native children: current knowledge and future prospects. Ann. N. Y. Acad. Sci 1136, 126-136 (2008).

37. Gehlert, S. et al. Targeting health disparities: a model linking upstream determinants to downstream interventions. Health Aff. 27, 339-349 (2008).

38. Braveman, P. \& Gottlieb, L. The social determinants of health: it's time to consider the causes of the causes. Public Health Rep. 129(Suppl 2), 19-31 (2014).

39. Jackson, C. L., Walker, J. R., Brown, M. K., Das, R. \& Jones, N. L. A workshop report on the causes and consequences of sleep health disparities. Sleep 43, zsaa037 (2020).

40. Alcántara, C. et al. Stress and sleep: results from the Hispanic community health study/study of Latinos sociocultural ancillary study. SSM Popul. Health. 3, 713-721 (2017).

41. Johnson, D. A. et al. The social patterning of sleep in African Americans: associations of socioeconomic position and neighborhood characteristics with sleep in the Jackson Heart Study. Sleep 39, 1749-1759 (2016).

42. John-Henderson, N. A., Palmer, C. A. \& Thomas, A. Life stress, sense of belonging and sleep in American Indian college students. Sleep Health 5, 352-358 (2019).

43. Carnethon, M. R. et al. Disparities in sleep characteristics by race/ethnicity in a population-based sample: Chicago Area Sleep Study. Sleep Med. 18, 50-55 (2016).

44. Gillis, B. T., Shimizu, M., Philbrook, L. E., \& El-Sheikh, M. Racial disparities in adolescent sleep duration: physical activity as a protective factor. Cultur. Divers. Ethnic Minor. Psychol. (2020).

45. Grandner, M. A., Williams, N. J., Knutson, K. L., Roberts, D. \& Jean-Louis, G. Sleep disparity, race/ethnicity, and socioeconomic position. Sleep Med. 18, 7-18 (2016).

46. Guglielmo, D., Gazmararian, J. A., Chung, J., Rogers, A. E. \& Hale, L. Racial/ethnic sleep disparities in US school-aged children and adolescents: a review of the literature. Sleep Health 4, 68-80 (2018).

47. Hall, M. H. et al. Race and financial strain are independent correlates of sleep in midlife women: the SWAN sleep study. Sleep 32, 73-82 (2009).

48. Egan, K. J., Knutson, K. L., Pereira, A. C. \& von Schantz, M. The role of race and ethnicity in sleep, circadian rhythms and cardiovascular health. Sleep Med. Rev. 33, 70-78 (2017).

49. Jackson, C. L., Redline, S. \& Emmons, K. M. Sleep as a potential fundamental contributor to disparities in cardiovascular health. Annu. Rev. Public Health 36, 417-440 (2015).

50. Johnson, D. A. et al. Association between sleep apnea and blood pressure control among blacks: Jackson Heart Sleep Study. Circulation 139, 1275-1284 (2019).

51. Seixas, A. A. et al. Benefits of community-based approaches in assessing and addressing sleep health and sleep-related cardiovascular disease risk: a precision and personalized population health approach. Curr. Hypertens. Rep. 22, 1-18 (2020).

52. Curtis, D. S., Fuller-Rowell, T. E., El-Sheikh, M., Carnethon, M. R. \& Ryff, C. D. Habitual sleep as a contributor to racial differences in cardiometabolic risk. Proc. Natl. Acad. Sci. USA 114, 8889-8894 (2017).

53. Zizi, F. et al. Race/ethnicity, sleep duration, and diabetes mellitus: analysis of the National Health Interview Survey. Am. J. Med. 125, 162-167 (2012).

54. Hokett, E. \& Duarte, A. Age and race-related differences in sleep discontinuity linked to associative memory performance and its neural underpinnings. Front. Hum. Neurosci. 13, 176 (2019).

55. Heissel, J. A., Levy, D. J. \& Adam, E. K. Stress, sleep, and performance on standardized tests: understudied pathways to the achievement gap. AERA Open 3, 2332858417713488 (2017).

56. Maciag, M. Diversity on the Force: Where Police Don't Mirror Communities. Washington, DC: Governing. Retrieved, 8, 1-13. http:// images.centerdigitaled.com/documents/policediversityreport.pdf.

57. Appiah, O., Knobloch-Westerwick, S. \& Alter, S. Ingroup favoritism and outgroup derogation: effects of news valence, character race, and recipient race on selective news reading. J. Commun. 63, 517-534 (2013).

58. Navarrete, C. D., McDonald, M. M., Molina, L. E. \& Sidanius, J. Prejudice at the nexus of race and gender: an outgroup male target hypothesis. J. Pers. Soc. Psychol. 98, 933-945 (2010).

59. Valla, L. G. et al. Not only whites: racial priming effect for black faces in black people. Basic Appl. Soc. Psychol. 40, 195-200 (2018).

60. Hatchett, B. F., Holmes, K., Duran, D. A. \& Davis, C. African Americans and research participation: the recruitment process. J. Black Stud. 30, 664-675 (2000).

61. Gilmore-Bykovskyi, A. L. et al. Recruitment and retention of underrepresented populations in Alzheimer's disease research: a systematic review. Alzheimers Dement. 5, 751-770 (2019).

62. Bonevski, B. et al. Reaching the hard-to-reach: a systematic review of strategies for improving health and medical research with socially disadvantaged groups. BMC Med. Res. Methodol. 14, 42 (2014). 
63. Hughes, T. B., Varma, V. R., Pettigrew, C. \& Albert, M. S. African Americans and clinical research: evidence concerning barriers and facilitators to participation and recruitment recommendations. Gerontologist 57, 348-358 (2017).

64. Roberts, S. O., Bareket-Shavit, C., Dollins, F. A., Goldie, P. D. \& Mortenson, E. Racial inequality in psychological research: Trends of the past and recommendations for the future. Perspect. Psychol. Sci. 15, 1295-1309 (2020).

65. Bell, M. P., Berry, D., Leopold, J., \& Nkomo, S. Making Black Lives Matter in academia: a black feminist call for collective action against anti-blackness in the academy. Gend. er Work Organ. (2020).

66. James, L., James, S. \& Vila, B. The impact of work shift and fatigue on police officer response in simulated interactions with citizens. J. Exp. Criminol. 14, 111-120 (2018).

67. Mitler, M. M. et al. Catastrophes, sleep, and public policy: consensus report. Sleep 11, 100-109 (1988).

68. Landrigan, C. P. et al. Effect of reducing interns' work hours on serious medical errors in intensive care units. N. Engl. J. Med. 351, 1838-1848 (2004).

69. Kecklund, G. \& Axelsson, J. Health consequences of shift work and insufficient sleep. BMJ 355, i5210 (2016).

70. Garbarino, S. et al. Sleep apnea, sleep debt and daytime sleepiness are independently associated with road accidents: a crosssectional study on truck drivers. PLoS ONE 11, e0166262 (2016).

71. Luyster, F. S., Strollo, P. J., Zee, P. C. \& Walsh, J. K. Sleep: a health imperative. Sleep 35, 727-734 (2012).

72. Global Council on Brain Health. The brain-sleep connection: GCBH recommendations on sleep and brain health. American Association of Retired Persons. https://www.aarp.org/content/dam/aarp/health/healthy-living/2017/01/gcbhrecommendationssleep-and-brain-health-aarp.pdf (2016).

73. Redeker, N. S. et al. Workplace interventions to promote sleep health and an alert, healthy workforce. J. Clin. Sleep Med. 15, 649-657 (2019).

74. Scullin, M. K. The eight hour sleep challenge during final exams week. Teach. Psychol. 46(1), 55-63 (2019).

75. Hu, X. et al. Unlearning implicit social biases during sleep. Science 348, 1013-1015 (2015).

76. Palimaru, A. I. et al. Understanding sleep facilitators, barriers, and cultural dimensions in Native American urban youth. Sleep Health 6, 478-488 (2020).

77. Tavernier, R. \& Adam, E. K. Text message intervention improves objective sleep hours among adolescents: the moderating role of race-ethnicity. Sleep Health 3, 62-67 (2017).

78. Seixas, A. A. et al. Culturally tailored, peer-based sleep health education and social support to increase obstructive sleep apnea assessment and treatment adherence among a community sample of blacks: study protocol for a randomized controlled trial. Trials 19, 1-16 (2018)

79. Wright, K. P. et al. Sleep in university students prior to and during COVID-19 stay-at-home orders. Curr. Biol. 30, R783-R801 (2020).

80. Lowe, C. J., Safati, A. \& Hall, P. A. The neurocognitive consequences of sleep restriction: a meta-analytic review. Neurosci. Biobehav. Rev. 80, 586-604 (2017).

81. Meltzer, L. J., Walsh, C. M., Traylor, J. \& Westin, A. M. L. Direct comparison of two new actigraphs and polysomnography in children and adolescents. Sleep 35, 159-166 (2012).

82. Weiss, A. R., Johnson, N. L., Berger, N. A. \& Redline, S. Validity of activity-based devices to estimate sleep. J. Clin. Sleep Med. 6, 336-342 (2010).

83. Carney, C. E. et al. The consensus sleep diary: standardizing prospective sleep self-monitoring. Sleep 35, 287-302 (2012).

84. Buysse, D. J., Reynolds, C. F., Monk, T. H., Berman, S. R. \& Kupfer, D. J. The Pittsburgh Sleep Quality Index: a new instrument for psychiatric practice and research. Psychiatry Res. 28, 193-213 (1989).

85. Akerstedt, T. \& Gillberg, M. Subjective and objective sleepiness in the active individual. Int. J. Neurosci. 52, 29-37 (1990).

86. Crowne, D. P. \& Marlowe, D. A new scale of social desirability independent of psychopathology. J. Consult. Psychol. 24, 349-354 (1960).

87. Grove, R. \& Prapavessis, H. Preliminary evidence for the reliability and validity of an abbreviated profile of mood states. Int. J. Sport Psychol. 23, 93-109 (1993).

88. Foster, J. L. et al. Shortened complex span tasks can reliably measure working memory capacity. Mem. Cogn. 43, 226-236 (2015).

89. Raven, J. C. Raven's progressive matrices (Western Psychological Services, Los Angeles, 1938).

90. Sim, J. J., Correll, J. \& Sadler, M. S. Understanding police and expert performance: when training attenuates (vs. exacerbates) stereotypic bias in the decision to shoot. Pers. Soc. Psychol. Bull. 39, 291-304 (2013).

\section{Acknowledgements}

The work was supported by a University Research and Scholarship Achievement Award (S.N., M.K.S., M.R.H.). M.K.S. was supported by NSF DRL 1920730 and NSF CAREER 1943323.

\section{Author contributions}

M.K.S., M.R.H., A.C., S.N. designed the experiment; S.N. collected data; M.K.S., S.N. analyzed data; M.K.S., M.R.H., A.C. edited the manuscript; M.K.S. and S.N. wrote the manuscript.

\section{Competing interests}

The authors declare no competing interests.

\section{Additional information}

Correspondence and requests for materials should be addressed to M.K.S.

Reprints and permissions information is available at www.nature.com/reprints.

Publisher's note Springer Nature remains neutral with regard to jurisdictional claims in published maps and institutional affiliations. 
(c) (i) Open Access This article is licensed under a Creative Commons Attribution 4.0 International cc) License, which permits use, sharing, adaptation, distribution and reproduction in any medium or format, as long as you give appropriate credit to the original author(s) and the source, provide a link to the Creative Commons licence, and indicate if changes were made. The images or other third party material in this article are included in the article's Creative Commons licence, unless indicated otherwise in a credit line to the material. If material is not included in the article's Creative Commons licence and your intended use is not permitted by statutory regulation or exceeds the permitted use, you will need to obtain permission directly from the copyright holder. To view a copy of this licence, visit http://creativecommons.org/licenses/by/4.0/.

(C) The Author(s) 2020 